Nahla O Tawfik

MBCHB, MSc, PhD (Asst Prof)

Rana Kh Atarbashe

BDS, MSc (Asst. Lec.)

\section{Amlodipine and Oral Health}

\author{
Department of Dental Basic Science \\ College of Dentistry, University of Mosul \\ Department of Dental Basic Science \\ College of Dentistry, University of Mosul
}

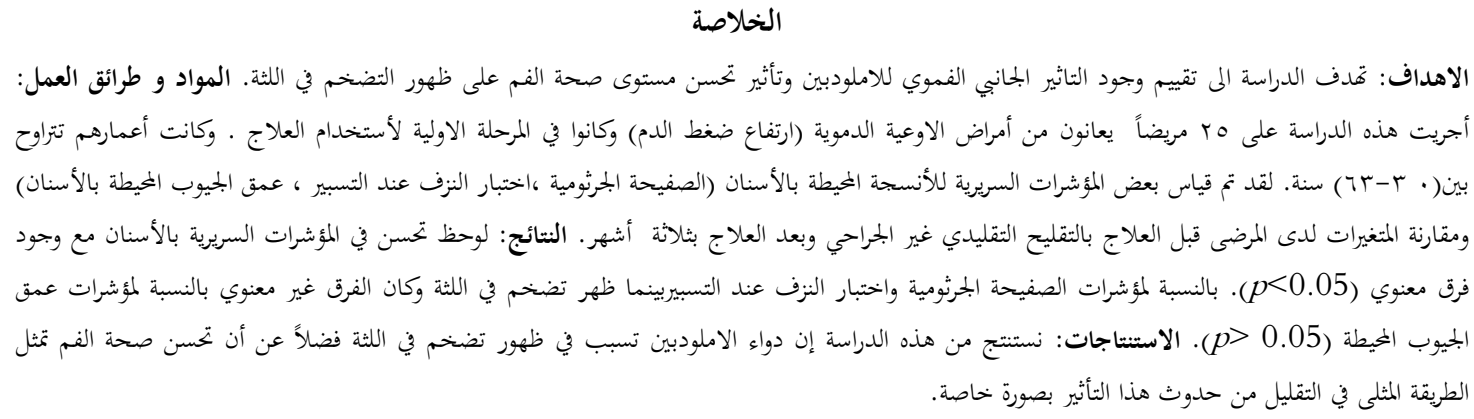

\begin{abstract}
Aims: To evaluate the oral side effect of amlodipine in patients with cardiovascular disease, also to study the effect of improving oral health on the possibility of development of gingival over growth. Materials and Methods: The study was conducted on 25 patients (pretreated group) with cardiovascular disease who had been prescribed amlodipine for the first time, aged ranged between 3063 years. Clinical examinations (plaque index (PI), bleeding on probing (BOP), probing pocket depth (PPD) and gingival over growth scores) were conducted under standardized illumination with plain dental mirror and a periodontal probe. The screening was done twice, the 1st assessment was collected at base line (pretreatment) visit before the first dose of the amlodipine and they received non surgical periodontal therapy (scaling, root planning and home care instruction) to get them to base line, but the 2nd assessment was done at the end of trial period at 12 week assessments (post treated). Results: The result obtained showed that the mean values of PI and BOP in post group were significantly lower than pre group $(p<0.05)$, While for the PPD, GO the mean values in the post group were higher than mean value in the pre group with significant difference for GO $(p<0.05)$ and no significant difference for PPD $(p>0.05)$.Conclusion: The study concluded that amlodipine therapy had got its influence on GO and that improvement in oral health represent a scientifically sound complementary intervention in reducing both the occurrence of GO and inflammatory levels in the systemic circulation.
\end{abstract}

Keyword: amlodipine, gingival overgrowth, plaque index, bleeding on probing, probing pocket depth.

Tawfik NO, Atarbashe RKH. Amlodipine and oral health. Al-Rafidain Dent J. 2014; 14(1):111-114.

Received: 3/11/2012 Sent to Referees: 5/11/2012 Accepted for Publication: 31/1/2013

\section{INTRODUCTION}

Amlodipine is a dihydroperidine calcium channel blocker (CCB), used for treatment of hypertension and angina pectoris (stable and prinzmetal's angina). It is given orally in a dose of $2.5-10 \mathrm{mg}$ once daily. It is well absorbed following oral administration, it exhibits very slow kinetics of onset and offset of blockade; with peak blood concentration occurring after 6 to 12 hours. It has a prolonged terminal elimination half life of 30 to 50 hours and extensively metabolized in the liver. ${ }^{(1)}$

Many adverse effects have been reported with amlodipine, such as; headache, leg edema, flushing, and palpitation. Headache and leg edema were most frequently reported and were generally mild to moderate in severity. ${ }^{(1,2)}$ 
Other, rare side effects have been reported such as: chest pain, gingival overgrowth and dry mouth..$^{(1)}$

Drugs associated with GO can be broadly divided into three categories; Anticonvulsants, CCBs, and immunosuppressant. ${ }^{(3)}$

The pathogenesis of drug influenced gingival enlargement suggests that it is multifactorial including; age, genetic predisposition, pharmacokinetic variables, drug induced alteration in gingival connective tissue homeostasis, plaque induced inflammatory changes and drug induced action on growth factors. ${ }^{(4)}$

It is hypothesized that non inflamed gingival fibroblasts are less active or even quiescent and do not respond to circulating drugs.While the fibroblasts within inflamed tissue are in an active state, as a result of inflammatory mediators and endogenous growth factors. ${ }^{(5)}$

The aims of this study were to evaluate the oral side effect of amlodipine in patients with cardiovascular disease, also to study the effect of improving oral health on the possibility of development of GO.

\section{MATERIALS AND METHODS}

This cohort study was conducted at outpatient clinic in Ibn Sina Teaching Hospital in Mosul City, from October 2010 to March 2011.

The study includes patients had been prescribed amlodipine therapy for the 1st time. This sample group consisted of 25 patients (14 males, 11 females), their age ranged between (30-63).

The design of this study was a 12 weeks open trial. It was suggested that 8 weeks was sufficiently long enough to register any clinically significant changes in the parameters studied. ${ }^{(6)}$

All patients had professional diagnosis for which they had prescribed the drug. The patients in this group were provided with $10 \mathrm{mg}$ amlodipine (Amaday) tablet (Ajanta Pharma- India).

Any patients taking anticonvulsants, immunosuppressants, or any other medications known to produce gingival enlargement were excluded from the study. Female patients enrolled in this study were not pregnant, lactating nor taking oral contraceptive pills.

All subjects participated were examined to assess the periodontal status of their upper and lower teeth by using Sterilized dental mouth mirror, periodontal probe, and tweezers. (Planmeca-Finland)

The screening was done twice, the $1^{\text {st }}$ assessment was collected at base line (pretreatment) visit before the first dose of the amlodipine and they received non surgical periodontal therapy (scaling, root planning and home care instruction) to get them to base line, but the $2^{\text {nd }}$ assessment was done at the end of trial period at 12 week assessments (post treatment). ${ }^{(7)}$

Clinical Assessment include: plaque index (8) Bleeding on Probing Index ${ }^{(9)}$ and Probing Pocket Depth. ${ }^{(10)}$

\section{Gingival Enlargement ${ }^{(11)}$}

The degree of gingival enlargement was scored as follows:

Grade 0: no signs of gingival enlargement. Grade I: enlargement confined to interdental papilla.

Grade II: enlargement involves papilla and marginal gingival.

Grade III: enlargement covers three quarters or more of the crown.

Statistical analysis of data were conducted using SPSS 17 for windows software. A $p$ value of $\leq 0.05$ was considered statistically significant, the t- test was used for the analysis of data. ${ }^{(12)}$

\section{RESULTS}

Table (1) demonstrates that the mean values of PI and BOP in post group were significantly lower than pre group, While for the PPD, GO, the mean values in the post group were higher than mean value in the pre group with significant difference for GO and no significant differencefor PPD. 
Table (1): Comparison between pre and post reading of clinical parameters of the 1st use group

\begin{tabular}{lcccc}
\hline \multicolumn{2}{c}{ Parameters } & Pre & Post & \multirow{2}{*}{$\boldsymbol{p}$-value } \\
\cline { 3 - 4 } & & Mean \pm SD & Mean \pm SD & \\
\hline PI & score & $1.555 \pm 0.826$ & $0.327 \pm 0.207$ & $0.000^{* *}$ \\
BOP & score & $0.703 \pm 0.379$ & $0.159 \pm 0.284$ & $0.001^{* *}$ \\
PPD & score & $2.979 \pm 0.356$ & $3.142 \pm 0.579$ & 0.366 \\
GO & score & $0.00 \pm 0.000$ & $0.67 \pm 0.9$ & $0.012^{*}$ \\
\hline
\end{tabular}

* significant at the 0.05 level, ** significant at the 0.01 level.

\section{DISCUSSION}

Patients with periodontal disease (PD) having a periodontal pocket, means an area especially prone for bacterial dissemination into the systemic circulation. The highest prevalence of PD and cardiovascular disease is encountered in middle and old age people. During the last years, CCB reached the first line of treatment, a level of evidence recommendation in treating coronary heart disease. ${ }^{(13)}$ World Health Organization ${ }^{(14)}$ has been strongly advocated for a good oral health, for integrating the prevention and health promotion policies between oral and general health. PD results in higher systemic levels of C-reactive protien (CRP) and interleukine-6- (IL-6). These elevated inflammatory factors may increase inflammatory activity in atherosclerotic lesions and potentially increasing the risk for cardiovascular events. ${ }^{(15)}$

Gingival enlargement can be observed after a few weeks or after a few years from the beginning of the treatment, being reversible after interruption of the drug that is generating it, a fact that underlines the necessity of periodic, specialized examinations. ${ }^{(16)}$

The occurance of GO in patients taking amlodipine differ from other dihydropyridines. ${ }^{(17)}$ Firstly; due to the slow elimination of amlodipine with resulting long duration of its action. ${ }^{(18)}$ Second, amlodipine is more polar than other dihydropyridines, with $\mathrm{pKa}$ value 8.7. Thus, the drug may not pass through cell membrane without an active transport mechanism. ${ }^{(19)}$

In this study, the comparison between before and after amlodipine administration showed there were no reduction in all the clinical parameter after treatment with amlodipine

The mean sites that bleed on probing, mean plaque amount are reduced after 3 months duration and the differences are significant. Mean probing depth is increased in post treated patients but the difference is not significant.

The degree of plaque control is considerd to be the most important among the aforementioned factors. ${ }^{(18)}$ The role of dental plaque as a co-factor in the etiology of GO was recognized in the latest PD classification system. ${ }^{(20)}$

Inflammation of the gingival tissue from the bacterial plaque and the subsequent development of gingival crevicular fluid may allow sequestration of the amlodipine, thus predisposing the tissue to a localized, toxic effect and to the development of GO. ${ }^{(16)}$ Apoptosis is a process that acts in concert with mitosis to preserve cellular homeostasis or to facilitate tissue remodeling during development. Amlodipine was well known as a CCB and inhibits the calcium influx from extracellular fluid.. This inhibition of apoptosis in the epithelium leads to cell accumulation, resulting in GO. ${ }^{(21)}$

The results of this study indicated that oral hygiene plays a decisive role in the development of GO and the incidence can be controlled successfully, even under continues administration of CCBs, by meticulous professional and individual oral hygiene, however not all patients with good oral and dental hygiene were free from GO. Seymour et al., ${ }^{(4)}$ showed that the selectivity of the GO to particular regions of the mouth and only in some patients,suggested a genetic predisposition that may interact with the local environment resulting in GO. 


\section{CONCLUSIONS}

Gingival overgrowth occurred in patients treated with amlodipine and oral hygiene plays a decisive role in the development of GO and the incidence can be controlled successfully by meticulous professional and individual oral hygiene.

\section{REFERENCES}

1. Food and Drug Administration (2010). Center for drug evaluation and research. Availalable at: http: /www.fda.gov/cder/drug/ infosheats/ patient/ amlodipine.htm.

2. Murdoch D, Heel RC. Amlodipine: a review of its pharmacodynamic and pharmacokinetic properties and therapeutics use in cardiovascular disease. Drugs. 1991; 41: 478-505.

3. Triveni MG, Rudrakshi C, Mehta DS. amlodipine-induced gingival overgrowth. J Indian Soc periodontol. 2009; 13 : 160-163.

4. Seymour RA, Thomson JM, Ellis JS. The pathogenesis of drug induced gingival overgrowth.. $J$ Clin periodontol.1996; 23: 165-175.

5. Stein hauer T, Bsoul SA, Terezhalmy GT. Risk stratification and dental management of the patient with cardiovascular diseases. Part II: Oral disease burden and principles of dental management. Quin Tessence Int. 2005; 36 (3): 209-236.

6. Lafzi A, Farahani RMZ, Shoja MAM. Amlodipine-induced gingival hyperplasia. Med Oral Patol Oral Cir Bucal.2006; 11:E480-482.

7. Meraw SJ, Sheridan PJ. Medically induced gingival hyperplasia. Mayo Clin Proc.1998; 73: 1196-1199.

8. Silness J, Löe H : Periodontal disease in pregnancy (II) : correlation between oral hygiene and periodontal conditions. Acta Odontol Scand.1964; $22: 121-135$.

9. Greenstein G, Caton J, Polson AM. Histologic characteristics associated with bleeding after probing and visual signs of inflammation. J Periodontol. 1981; 52: 420-425.

10. Ramfjord SP. The periodontal index (PDI). J Periodontol.1967; 38: 602.
11. Bökenkamp A, Bohnhorst B, Beir C. Nifedipine aggravates cyclosporine Ainduced hyperplasia. Pediatr Nephrol. 1994; 8:181.

12. Howitt D, Cramer D (1999). A guide to computing stastics with SPSS for windowstm, 2nd Edi, Pearson Education Limited, Essex. England.

13. Humphrey LL, Fue R, Buckle Y. Periodontal disease and coronary heart disease incidence: A systematic review and meta-analysis. Journal of General Internal Medicine: Official Journal of the society for research and education in primary care. Internal medicine. 2008; 23: 2079-2086.

14. World Health Organization. Continuous improvement of oral health in the 21 st century. The approach of the WHO Global Oral Health Programme. The World Oral Health Report. 2003; 23: 1-22.

15. Gani DK, Lakshmi D, Krishnan R, Emmadi P. Evaluation of C-reactive protein and interleukin-6 in the peripheral blood of patients with chronic periodontitis. $J$ Indian Soc Periodontol.2009; 13 (2):64-68.

16. Balan H, Popescu E, Angelescu G. Pathologic crossroads: cardiovascular diseases, periodontal diseases and calcium antagonists. $J$ Med Life.2011; 154(1): 2-10.

17. Nery EB, Edson RG, Lee KK, Pruthi VK, Watson J. prevalence of nifedipine-induced gingival hyperplasia. J periodontol.1995; 66: 572-578.

18. Agnihotri R, Bhat GS, and Bhat KM. Amlodipine induced gingival overgrowth: considerations in a geriatric patient. Geriatr Gerontol Int. 2010; 11: 365-368.

19. Jorgensen MG. Prevalence of amlodipine related gingival hyperplasia. J periodontol. 1997; 68: 676-678.

20. Armitage GC. Development of a classification system for periodontal diseases and conditions. Annals of Periodontol. 1999; 4: 1-6, 67.

21. Abdollahi M, Radfar M. A Review of drug-induced oral reactions. $J$ Contemp Dent Pract. 2003; 15 4(1): 10-31. 